\title{
DEPARTAMENTO DE ONCOLOGIA CUTÂNEA
}

\section{P0138 Síndrome do nevobasocelular (SNBC) - Apresentação de casos}

\author{
AUTORES: Coelho MAR, Cardoso LC, Miot H, Stolf HO. \\ INSTITUIÇÃO: Faculdade de Medicina de Botucatu - UNESP
}

INIRODUÇÃO: A SNBC, ou Síndrome de Gorlin-Goltz, é uma genodermatose rara, de difícil reconhecimento dado o pleomorfismo de sua expressão. 0 diagnóstico é clínico, associado a extensa investigação por imagens e exames histopatológicos. Ele deve ser precoce para permitir a prevenção de neoplasias múltiplas e de deformidades faciais e orais. Caso 1 - paciente masculino, 60 anos com início das manifestações aos 32 anos e diagnóstico realizado na mesma época. Não apresentava história familiar de SNBC ou outras síndromes, nem de exposição ao arsênico ou radiação. Exame clínico: múltiplos carcinomas basocelulares (CBCs) de distribuição predominantemente cefálica, no tronco e membros superiores, pits palmares, proeminência frontal e mandibular. A investigação radiológica revelou cistos mandibulares e presença de costela bífida. Foi submetido a tratamentos com eletrocauterização e curetagem, excisão cirúrgica, criocirugia, 5-fluouracil e atualmente, está em uso de imiquimod. Caso 2 - paciente masculino, 50 anos, com início das manifestações aos 34 anos e diagnóstico aos 49 anos. 0 exame clínico evidenciava inúmeros $\mathrm{CBCs}$, com distribuição em áreas fotoexpostas, pits palmares e proeminência frontal. A abordagem terapêutica compreendeu cirurgia excisional, criocirurgia e atualmente está em uso de acitretin $25 \mathrm{mg} / \mathrm{dia}$. Caso 3 - paciente feminina, 60 anos, branca, foi vista inicialmente por profissional odontológico aos 13 anos de idade por malformações da arcada dentária, defidos por exame histopatológico como cistos odontogênicos. Na segunda década de vida, apareceram múltiplos CBCs, sendo feito o diagnóstico de SNBC. Foi submetida a exéreses cirúrgicas sequenciais, com dano estético significativo. Caso 4 - paciente masculino, 58 anos, branco, com início das manifestações aos 41 anos e diagnósto realizado 3 anos depois. Foi submetido a tratamento das lesões com criocirurgia e excisão cirúrgica.

Discussão: Houve predomínio de pacientes no sexo masculino (75\%) e da raça branca (100\%), todos com história de exposição à radiação ultravioleta. Os dados clínicos mais evidentes foram a presença de múltiplos CBCs e os pits palmares. Achados de calcificação da foice e espinha bífida foram os mais encontrados. Embora fossem pacientes com idade média superior a 50 anos, brancos e com história de exposição a radiação ultravioleta, apenas um apresentava queratoses actínicas. A idade média ao diagnóstico foi de 36 anos, quando já estavam presentes múltiplas lesões. A modalidade terapêutica com maior freqüência foi a exérese cirúrgica, seguida da criocirurgia, ambas com resultados estéticos pobres após múltiplas intervenções. 0 motivo da apresentação é ressaltar a importância do diagnóstico precoce possibilitando alternativas terapêuticas mais satisfatórias não apenas oncológica mas também esteticamente.

\section{PO 139 Ictiose Hystrix associado ao pseudoainhum}

\author{
AUTORES: Suehara LY, Lazzarini R, Muller $\mathrm{H}$. \\ INSTITUIÇÃO: Clínica de Dermatologia da Santa Casa de São Paulo, SP
}

INTRODuçÃo: A Ictiose Hystrix é uma doença autossômica dominante, rara, caracterizada por lesões hiperceratósicas com formas nevóides. O pseudoainhum é uma doença adquirida ou congênita caracterizada pela formação progressiva de uma banda fibrótica de constrição nos pododáctilos que evoluem para autoamputação. Está associado a doenças como esclerodermia, vasculites e como neste caso, à hiperceratose.

Relato de Caso: L.S., 45 anos, sexo feminino, do lar, casada. Referia desde um ano de idade lesões da pele inicialmente eritematosas que evoluíram para placas intensamente hiperceratósicas e verrucosas, mais localizada no membro inferior direito. Há 3 anos formação de uma constrição na falange distal do terceiro pododáctilo esquerdo. Três filhos hígidos, sem história familiar, pais não consangüíneos. Ao exame físico: dermatose localizada nos membros superiores e inferiores (mais intensa à direita) caracterizada por pápulas de superfície verrucosa que confluem formando placas intensamente verrucosas com disposição zosteriforme. Nas regiões palmoplantares há intensa hiperceratose. Presença de constrição na falange distal do terceiro pododáctilo esquerdo. Biópsia da pele evidenciou epiderme difusamente espessada por acantose, papilomatose e hiperceratose.

Discussão: A Ictiose Hystrix abrange quatro subtipos. Este caso enquadra-se o tipo de Curth-Macklin, devido ao 
comprometimento palmoplantar, lesões nevóides e ausência de alterações sistêmicas. Os subtipos descritos na literatura são doenças autossômicas dominantes, porém, nos diversos relatos de casos, não há comprometimento de outros membros da família. A grande variedade de apresentações clínicas dos pacientes dificulta a classificação correta, devido a uma variância da expressividade genética. A associação da Ictiose Hystrix com pseudoainhum é rara. Motivo DA APRESENTAÇão: Raridade do caso e dificuldade de classificação.

\section{PO 140 Perniose familiar}

AUTORES: Figueiredo HC, Barbosa ALBP, Passos TV Gontijo GT.

INSTITUIÇÃO: Serviço de Dermatologia do Hospital das Clínicas de Belo Horizonte, MG

INIRODuç̃̃o: Perniose é relativamente frequente em países onde o clima é frio e úmido porém, rara em nosso meio. Caracteriza-se por edema, dor, fissuras, úlceras e pápulas eritêmato-violáceas localizadas preferencialmente em áreas acrais, principalmente dorso dedos das mãos e pés, nariz e pavilhão auricular. Há predisposição genética e o frio e a umidade são os principais desencadeantes. Diagnóstico diferencial importante se faz com as lesões acrais do lúpus eritematoso. Sugere-se que a causa da perniose seja o vasoespasmo ou uma vasculite cutânea de pequeno grau. Os achados histológicos principais são necrose de queratinócitos, edema na derme com infiltrado inflamatório superficial, profundo e periécrino composto predominantemente por células $T$, poucos macrófagos e raras células B.

RELATO DE CASO: Trata-se de uma família em que o pai e os três filhos são acometidos. Não há história de consanguinidade. Pai: G.R.P., 40 anos, masculino, faiodérmico, servente de pedreiro, natural de Dores de Guanhães - MG, residente em Ibirité - MG. Filhos: G.S.R., 18 anos, masculino; R.S.P., 15 anos, masculino; V.S.P., 10 anos, feminina. $O$ quadro dermatológico é semelhante nos quatro casos, variando em intensidade: presença de lesões eritêmato-violáceas, algumas ceratóticas, localizadas nos pavilhões auriculares, ponta do nariz, dorso das articulações dos dedos das mãos e pés. Formação de pseudo-ainhum nos dedos das mãos e pés e cicatrizes atróficas nas polpas digitais. Há piora das lesões com o frio e presença de lividez, eritema e cianose nas mãos quando em contato com água fria. Exames laboratoriais (quatro casos): FAN e pesquisa de crioglobulinas negativos; transaminases, LDH, CK total, aldolase e complemento normais. A.P.: hiperceratose ortoceratótica e acantose irregular, degeneração hidrópica da basal, derme com vasos capilares dilatados associados a infiltrado inflamatório linfo-histiocitário superficialmente; há incontinência pigmentar e discreto edema papilar.

Dıscussão: Há pou cos casos da doença relatados em países de clima tropical como o Brasil, principalmente casos familiares. $O$ curso da doença é crônico com perío dos de agudização nos meses de inverno. Em nosso país, como não somos bem adaptados a temperaturas mais frias (ambientes climatizados, torneiras com água quente), essas agudizações podem ser catastróficas, ocasionando perda de função das mãos e pés nesses períodos.

Motivo DA APRESENTAÇÃo: Raridade de caso familiar da doença.

\section{PO141 Atrofia de Sudek}

AUTORES: $\quad$ Badaró MMI, Ferreira FR, Heras CAB, Di Santis EP, Mandelbaum SH.
INSTITUIÇÃO: Serviço de Dermatologia do Dr Samuel H. Mandelbaum - Taubaté, SP.

INTRODUÇÃo: Atrofia de Sudek ou distrofia simpática reflexa é uma síndrome dolorosa, acompanhada ou não de sintomas vasomotores, cuja fisiopatologia permanece desconhecida. Parece ocorrer uma hipersensibilidade às catecolaminas, geralmente em decorrência de traumas, doenças internas, malignidades, medicamentos ou idiopática. Ocorre dor intensa, geralmente em queimação, e alterações autônomas (edema, hipo ou hiperidrose, alterações tróficas da pele, TCSC, músculos e osteoporose).

Relato de Caso: G.V.C., 13 anos feminina, branca, babá, natural e procedente de Lorena-SP. Há 8 meses apresentava edema frio eritemato-violáceo e artralgia em mão direita. Sem sintomas sistêmicos. Exames complementares: hemograma: sem alterações; VHS: 5; FAN: não reagente; FR: negativo; VDRL: negativo; Ac anti-Scl 70: negativo; RX da mão D: osteoporose; Cintilografia óssea: hipercaptação do radiofármaco. RX de tórax: normal; USG de abdômen: normal. Exame histopatológico: epiderme preservada. Na derme as fibras colágenas são bem distribuídas com raros histiócitos. Tratamento: calcitonina e deflazcort $6 \mathrm{mg} / \mathrm{d}$.

Discussão: Trata-se de um caso de atrofia de Sudek não relacionado às causas mais comuns descritas na literatura (trauma, doenças internas, malignidades, uso de medicamentos), já com seqüelas irreversíveis (osteoporose).

Motivo da APRESENTAÇÃo: Raridade do caso. 


\title{
PO 142 Síndrome de Rothmund Thomson - Relato de caso
}

\author{
AUTORES: Romanini JS, Ferreira FR, Andraus EM, Mantovani K, Martelotte M. \\ INSTITUIÇÃO: Serviço de Dermatologia do Dr Samuel H. Mandelbaum - Taubaté, SP
}

INTRODUÇÃO: A síndrome citada é uma entidade rara de herança autossômica recessiva com alteração no gene RECQ 4 do cromossomo 8 e até 2002 cerca de 200 casos foram reportados. As manifestações dermatológicas são placas reticulares, atróficas, hiperpigmentadas, com telangectasias. Freqüentemente acompanhada por catarata juvenil em 52\% dos casos, microfitalmia, microcórnea, estrabismo e glaucoma. Observa-se também nariz em sela, defeitos ósseos congênitos, distúrbio de crescimento de cabelos, unhas e dentes, além de hipogonadismo.

História e Manifestações: Paciente de 24 anos do sexo masculino, natural e procedente de Taubaté. Segundo relato do paciente, foi feito estudo genético e confirmada a doença na E.P. de Medicina no ano de 1992, e registro $n^{\circ} 776135$. O paciente iniciou quadro dermatológico aos 3 anos de idade, acompanhado de hipodesenvolvimento pondero-estatural. Aos 11 anos foi submetido a cirugia de catarata do olho esquerdo. QuADRo CLínICo: Alterações dermatológicas: 1. Todo tegumento: áreas de hipopigmentação com telangectasias-poiquilodermia. 2. Unhas: distrofia da lâmina e ceratose subungueal. 3. Dentes: desenvolvimento rudimentar. 4. Cabelos: finos e esparsos. Alterações oftalmológicas: HD: glaucoma do OE secundário a afacia, alta miopia de ambos os olhos, exotropia sensorial do OE.

Dıscussão e Conclusão: Trata-se de uma genodermatose rara, com uma gama variada de manifestações clínicas, o que torna mandatória a avaliação clínica minuciosa e multidiciplinar. Esta doença é de baixa prevalência e apresenta-se com exuberância clínica neste caso, no qual foram avaliados e diagnosticados os principais comemorativos que compõem tal síndrome.

\section{PO 143 Hanseníase virchowiana mimetizando tumor de testículo}

\author{
AUTORES: Belo CCT, Vieira AFM, Belo MTCT, Lopes FG, Kaisermann M. \\ INSTITUIÇÃO: Universidade Gama Filho, 7ạ Enfermaria da Santa Casa da Misericórdia do Rio de Janeiro, RJ.
}

INTRODUçÃo: A hanseníase é uma doença infecciosa crônica que afeta mais de um milhão de pessoas em todo o mundo. O Brasil é o segundo país em número de casos entre os 15 países onde a doença é considerada endêmica. A hanseníase virchowiana caracteriza-se por infiltração difusa e progressiva do tegumento e nervos periféricos, podendo acometer diversos órgãos. 0 envolvimento testicular é raro e pode ocorrer como primeira manifestação da doença. Dor, esterelidade e impotência são os sintomas mais relatados.

Relato do Caso: W.F.A., masculino, 34 anos, pardo, solteiro, natural do Rio de Janeiro, pedreiro. Há um ano notou edema de membros inferiores e após seis meses aparecimento de nódulos cutâneos dolorosos, de tamanhos variáveis, nos membros superiores e inferiores além de aumento doloroso do escroto. Refere ainda perda ponderal de $5 \mathrm{~kg}$ e febre vespertina não aferida. Ao exame físico apresentava massa pétrea e dolorosa no escroto direito, epidídimo direito endurecido, linfonodos pal páveis na região inguinal direita e nódulos subcutâneos móveis, endurecidos, dolorosos e sem sinais flogísticos nos membros superiores, inferiores e dorso. A hipótese diagnóstica neste momento era de seminoma. Exames Complementares: Hemograma: $\mathrm{Hm}-4$ milhões/mm, Hb-9,3 g\%, $\mathrm{Ht}-31 \%$, série branca e plaquetas normais; bioquímica e provas funcionais hepáticas-normais; sorologia anti-HIV negativa; EPF - Ascaris lumbricoides e Strongiloides stercoralis; Alfafetoproteína - 2,81 ng/ml; Beta Gonadotrofina Coriônica - 0,00 Ul/ml; USG do escroto - presença de nódulo homogêneo no pólo superior do hemiescroto direito medindo $5,2 \times 2,8 \times 2,3 \mathrm{~cm}$. Epidídimo direito com ecogenicidade reduzida. Biópsia de gânglio inguinal direito: hanseníase virchowiana. Paciente iniciou tratamento com PQT-MB.

Discussão: $O$ testículo pode ser acometido no curso ou nos episódios reacionais da hanseníase virchowiana. As manifestações clínicas mais comumente descritas são dor, impotência, esterelidade, atrofia testicular e orquite. Nosso paciente apresentava massa pétrea próxima ao testículo e nódulos subcutâneos sugerindo neoplasia testicular com implante cutâneo. A avaliação histopatológica foi fundamental para elucidação diagnóstica.

Justificativa: Os autores justificam a apresentação deste trabalho, pois se trata de uma forma atípica de apresentação clínica da hanseníase virchowiana. 